\title{
Estimativa de área de vegetação secundária na Amazônia Legal Brasileira
}

\author{
Cláudio Aparecido ALMEIDA ${ }^{1}$, Dalton Morisson VALERIANO², Maria Isabel Sobral ESCADA³ , Camilo \\ Daleles RENNÓ ${ }^{4}$
}

\begin{abstract}
RESUMO
A vegetação secundária tem funçôes relevantes para os ecossistemas, tais como a fixação de carbono atmosférico, a manutenção da biodiversidade, o estabelecimento da conectividade entre remanescentes florestais, manutenção dos regime hidrológico e a recuperação da fertilidade do solo. O objetivo deste trabalho é, através de uma abordagem amostral, estimar a área ocupada por vegetação secundária na Amazônia Legal Brasileira (AML) em 2006. A amostragem se baseia em uma abordagem estratificada pelo grau de desflorestamento das cenas LANDSAT-TM que recobrem a AML. Foram selecionadas 26 cenas para o ano de 2006, distribuídas em sete estratos conforme o percentual de desflorestamento, nas quais foram mapeadas as áreas de vegetação secundária a partir de técnicas de classificação de imagens. Foi desenvolvido um modelo multivariado de regressão para estimar a área de vegetação secundária utilizando como variáveis independentes a área de desflorestamento, a área de hidrografia, a estrutura agrária, e área das unidades de conservação. A análise de regressão encontrou um $\mathrm{R}^{2}$ ajustado de 0,84 , e coeficientes positivos para a proporção de hidrografia na imagem $(2,055)$ e para a estrutura agrária $(0,197)$, e coeficientes negativos para o grau de desflorestamento na imagem $(-0,232)$ e para a proporção de Unidades de Conservaçáo na imagem $(-0,262)$. O modelo de regressão estimou uma área de $131.873 \mathrm{~km}^{2}$ de vegetação secundária para o ano de 2006. Aplicando uma simulaçáo Monte Carlo foi estimada uma incerteza de aproximadamente $12.445 \mathrm{~km}^{2}$ para a área.
\end{abstract}

PALAVRAS-ChaVE: Vegetação Secundária, Sensoriamento Remoto, Modelos Estatísticos, Dinâmica de uso e cobertura da terra

\section{Estimation of secondary vegetation area in the Brazilian Legal Amazon}

\begin{abstract}
Secondary vegetation has many relevant functions to the ecosystems such as atmospheric carbon fixation, maintenance of biodiversity, establishment of connectivity among forest remnants, maintenance of hydrological regime, and restoration of soil fertility. The objective of this work is to estimate the area occupied by secondary vegetation in the Brazilian Legal Amazon (BLA) for 2006 using a sampling scheme. The sampling is based on a stratified approach according to the degree of deforestation observed in the 229 TM-Landsat scenes that cover the BLA. Thus, 26 scenes were selected for 2006 and distributed into seven strata, according to their degree of deforestation, in which secondary vegetation areas were mapped. A regression model was constructed to estimate secondary vegetation area in the remaining images using deforestation area, hydrographic area, agrarian structure, and area of conservation units, as independent variables. The regression analysis found an adjusted $\mathrm{R}^{2}$ of 0.84 and positive coefficients for the proportion of hydrography in the image (2.055) and for the agrarian structure (0.197), while negative coefficients for the degree of deforestation in the image $(-0.232)$ as well as for the proportion of Conservation Unity(-0.262). Using the multivariate regression model, an area of $131,873 \mathrm{~km}^{2}$ of secondary vegetation was estimated for the year of 2006. Applying a Monte Carlo simulation we estimated an uncertainty of approximately $12,445 \mathrm{~km}^{2}$.
\end{abstract}

KEYWORDS: Secondary Vegetation, Remote Sensing, Statistical Models, Geoprocessing, Land use Dynamic.

\footnotetext{
1 Instituto Nacional de Pesquisas Espaciais - INPE, E-mail: claudio@dsr.inpe.br

2 Instituto Nacional de Pesquisas Espaciais - INPE, E-mail: dalton@dsr.inpe.br

3 Instituto Nacional de Pesquisas Espaciais - INPE, E-mail: isabel@dpi.inpe.br

${ }^{4}$ Instituto Nacional de Pesquisas Espaciais - INPE, E-mail: camilo@dpi.inpe.br
} 


\section{INTRODUÇÃO}

Dos cerca de 5 milhóes de $\mathrm{km}^{2}$ da Amazônia Legal Brasileira (AML), mais de 4 milhóes $\mathrm{km}^{2}$ eram originalmente florestados. Desde 1988, o Instituto Nacional de Pesquisas Espaciais (INPE) tem medido as taxas anuais de desflorestamento através do Projeto de Monitoramento da Floresta Amazônica Brasileira por Satélite (PRODES) (Câmara et al., 2006). Neste período as taxas de desflorestamento variaram entre 11.030 e $29.059 \mathrm{~km}^{2}$ /ano. Em 2007, o desflorestamento acumulado atingiu mais de $690.000 \mathrm{~km}^{2}$ (INPE, 2008), o que representa $16 \%$ da cobertura florestal original da AML.

Diversos estudos analisaram os efeitos do desmatamento na Amazônia ( Nobre et al., 1991; Laurance, 1999; Laurance et al., 2004; Fearnside, 2005) indicando entre eles, a redução de fertilidade do solo, erosão, alteraçôes nos regimes hidrológico local e global e emissão de gases de efeito estufa. Esses efeitos podem ser minimizados devido ao crescimento da vegetação secundária que se forma na área desflorestada. Essas áreas muitas vezes são utilizadas para atividades agropecuárias e quando perdem sua produtividade são abandonadas.

Brown e Lugo (1990) definem vegetação secundária como aquela formada a partir de distúrbios antrópicos na vegetação original. Nesse trabalho definimos como vegetação secundária, as áreas onde houve corte raso detectado pelo PRODES (INPE, 2008) e que após o abandono houve regeneração da vegetação.

A vegetação secundária pode prover diversos serviços ambientais como a remoção de carbono atmosférico, que contribui para atenuar a crescente emissão de gases de estufa para a atmosfera (Nobre \& Nobre, 2002). A taxa de remoção de carbono pela acumulação de biomassa é influenciada por fatores como o tipo, intensidade e tempo de uso da terra (Fearnside, 1996). Moran et al.(1994) encontraram uma alta variabilidade espacial nas taxas de crescimento secundário na Amazônia, atribuindo tais variaçóes à ocorrência ou não de queima completa na área convertida, viabilidade do banco de sementes, fertilidade sub-superficial dos solos e grau de inclinação do terreno.

Outra importante função da vegetação secundária é o estabelecimento da conectividade entre os remanescentes florestais podendo ter efeitos positivos para a manutenção da biodiversidade (STOUFFER et al., 2006).

A vegetação secundária também contribui com a recuperação da fertilidade do solo em agricultura itinerante (Martins, 2005). Juo e Mana (1996) e Szott et al. (1999) também discutem a importância da vegetação secundária para a ciclagem de nutrientes no processo de agricultura itinerante, permitindo a estabilidade do rendimento agrícola. Para entender a influência de indicadores sociais na formação de vegetação secundária Perz e Skole (2003) analisaram dados municipais dos censos demográficos e agropecuários de 1980 e 1991 combinados com dados orbitais. De acordo com esse estudo o menor tempo de uso da terra e a forma tradicional de usá-la (agricultura itinerante) tendem a aumentar a área de vegetação secundária. Ondas migratórias e usos não tradicionais (pastagem) diminuem a área de ocorrência. D'antona et al. (2006) encontraram forte influência do tamanho da propriedade no processo de conversão da cobertura da terra, e conseqüentemente na formação de vegetação secundária. $\mathrm{O}$ estudo mostrou também que propriedades menores tendem a apresentar florestas secundárias com ciclos de vida mais curtos devido à menor disponibilidade de terras. Ciclos de menor duração impedem a formação de vegetação secundária intermediária ou avançada, mantendo a área em constante utilização agrícola.

Diversos autores mapearam em escala local a ocorrência de vegetação secundária e encontraram relaçóes desta com os ambientes físico e sócio-econômico da regiāo (Alves \& Skole 1996; Nelson et al., 2000; Steininger, 2000; Roberts et al., 2002; Alves et al., 2003; Lu et al., 2003a; Espírito-Santo et al., 2005; ). Estimativas do total de área de vegetação secundária na AML foram realizadas através de métodos amostrais, considerando quase sempre um pequeno número de amostras, ou por medidas com base em dados de sensoriamento remoto de baixa resolução. Neeff et al. (2006), criaram um modelo estatístico a partir de relaçóes empíricas verificadas entre a ocorrência de vegetação secundária e a fração de floresta remanescente, inferindo para a AML em 2002, uma área total de floresta secundária de $161.000 \mathrm{~km}^{2}$ com uma incerteza estimada de $8 \%$. Esse estudo foi realizado a partir de estudos de caso realizados em sete áreas na Amazônia localizadas nos estados do Amazonas, Pará, Mato Grosso e Rondônia. Carreiras et al.(2006), utilizaram imagens SPOT/Vegetation e estimaram em $140.000 \mathrm{~km}^{2}$ a extensão da vegetação secundária na AML em 2000. Lucas et al. (2000) estimaram em $157.973 \mathrm{~km}^{2}$ a área coberta por vegetação secundária em 1992 na AML com base em imagens NOAA/AVHRR, de baixa resolução espacial.

Estudos de caso contribuem com o entendimento e fornecem informaçóes relevantes em escala local (Bernardes, 1998; Alves et al., 1999; Nelson et al., 2000; Steininger, 2000; Lu et al., 2003a;Espírito-Santo et al., 2005; Gehring et al., 2005), mas seus resultados não devem ser generalizados para a toda a AML.

Este estudo tem como objetivo estimar a área de ocorrência da vegetaçáo secundária a partir de um modelo preditivo de regressão multilinear nas áreas desflorestadas para o ano de 2006, considerando a macro-escala da AML. As estimativas se baseiam em um desenho amostral estratificado, cujo critério utilizado para estratificação é o grau de desflorestamento das imagens LANDSAT-TM. Os resultados desse trabalho 
fornecem subsídios para os estudos de balanço de carbono em escala regional e global e contribuem para o entendimento dos principais fatores que influenciam a variabilidade espacial da ocorrência da vegetação secundária.

\section{ÁREA DE ESTUDO}

A Amazônia Legal compreende os estados do Acre, Amapá, Amazonas, Mato Grosso, Pará, Rondônia, Roraima, Tocantins e parte do estado do Maranháo, correspondendo a uma área de aproximadamente 5 milhóes $\mathrm{de} \mathrm{km}^{2}$. Desse total, o projeto PRODES identifica como área com fisionomia florestal cerca de 4 milhôes de $\mathrm{km}^{2}$. O clima é do tipo equatorial, quente e úmido, com a temperatura variando pouco durante o ano, em torno de $26^{\circ} \mathrm{C}$.

Até a década de 60 , a ocupação humana trouxe poucas modificaçôes para o domínio da floresta amazônica, com exceção da redução da população indígena. A partir dos anos 70, a ocupação da Amazônia tornou-se prioridade nacional e governo federal passou a subsidiar a ocupação de terras para expansão pioneira. Dada a imensidão deste território, as políticas de ocupação procuraram combinar os empreendimentos de exploração econômica com estratégias geopolíticas (Costa, 1997). Foi neste período que alteraçôes ambientais mais significativas começaram a ocorrer na regiáo Amazônica, se estendendo até os dias atuais.

\section{MATERIAIS}

Nesta seção são apresentados os dados utilizados nas estimativas da vegetação secundária. Este trabalho se baseia no uso dos dados anuais do desflorestamento na AML produzidos pelo INPE, que são organizados e distribuídos pelas órbita/ ponto do satélite LANDSAT/TM. Assim, a grade de imagens Landsat/TM foi adotada como referência para a amostragem e a órbita/ponto como unidade amostral.

Foram utilizados dados de diferentes fontes, para a construçáo das variáveis do modelo, como mapas de desmatamento de 2006 (INPE, 2008), imagens Landsat/ TM de 2006, mapa de ecorregióes (IBAMA, 2006), mapa de estrutura agrária (IBGE, 2007), mapa de hidrografia (INPE, 2006) e de Unidades de Conservaçãoo (IBAMA, 2008). Esses dados são descritos a seguir.

\section{DADOS DO PRODES}

A série histórica do PRODES disponibilizada pelo INPE contém como classes temáticas a área ocupada por florestas, áreas ocupadas por hidrografia, áreas do tipo Não Floresta (ou seja ocupadas por formaçôes não florestais) e as áreas já desflorestadas separadas em desflorestamento acumulado até o ano de 1997, o desflorestamento no intervalo de 1997 a 2000 e o desflorestamento anual de 2000 a 2008. Estes dados estáo disponíveis na internet na página do PRODES (INPE, 2008) em arquivos digitais. Nesse estudo foram utilizados os dados de desflorestamento de 2006.

\section{IMAGENS LANDSAT-TM}

Para a identificação e mapeamento da vegetação secundária foram utilizadas as imagens LANDSAT-TM, estratificadas a partir do grau de desflorestamento observado em 2006 (área desflorestada/área original de floresta). Na Figura 1 encontram-se representadas as 229 cenas LANDSAT-TM que recobrem a AML, e seus respectivos graus de desflorestamento. As imagens utilizadas neste estudo estão marcadas com um círculo.

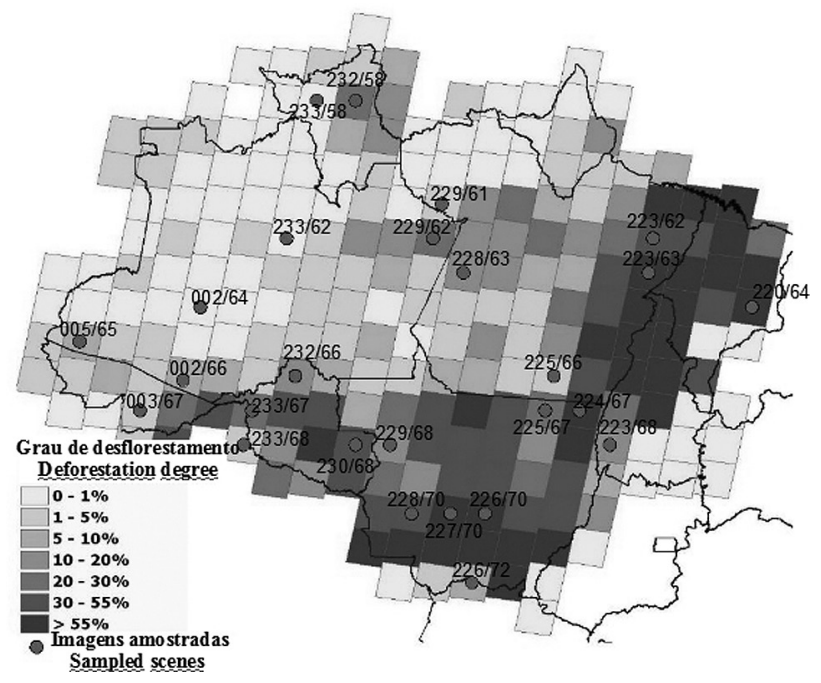

Figura 1 - Grau de desflorestamento das cenas da AML e cenas amostradas

\section{MAPA DE ECORREGIÕES}

De acordo com alguns estudos encontrados na literatura ( Odum, 1969; Moran et al., 2000; Nelson et al., 2000; Roberts et al., 2002; Neeff et al., 2006) fatores ambientais locais influenciam a formação de vegetação secundária. Assim, para representar as características do meio físico foi adotado nesse trabalho mapas de ecorregiōes. As ecorregiōes, segundo Loveland e Merchant (2004), agrupam os vários ambientes ecológicos amazônicos que exibem relativa homogeneidade dos ecossistemas. As ecorregiôes buscam sintetizar as principais características bióticas e abióticas locais. Para o Bioma Amazônia, Olson et al. (2001) mapearam 48 ecorregióes, esse mapeamento foi utilizado neste trabalho e encontra-se disponível na página do IBAMA (2006). Para permitir uma análise quantitativa as ecorregióes foram agrupadas em duas classes: florestadas e não-florestadas. 


\section{MAPA DE ESTRUTURA AGRÁRIA DA AMAZÔNIA LEGAL BRASILEIRA}

O grande extensão da AML faz com que esta região seja um mosaico de muitos ambientes, não só físicos, mas também histórico-culturais e sócio-econômicos (Hurtienne, 2005). Assim, buscando representar a diversidade de formas de uso da terra e os agentes associados a esses usos, foi utilizado o mapa de estrutura agrária da Amazônia Legal (IBGE, 2007). Neste estudo os dados foram agrupados segundo a concentraçáo fundiária em três classes: baixa, média e alta concentração fundiária.

\section{DADOS DE HIDROGRAFIA}

Miguez et al.(2007) descrevem a atividade agrícola como uma das principais atividades econômicas e forma de subsistência das famílias ribeirinhas da Amazônia, dentro de um sistema fortemente apoiado na agricultura itinerante, e que favorece a formação de vegetação secundária.

Para que fosse possível avaliar esta influência foi criado um índice que mostra quanto da área das cenas amostradas para o estudo, são ocupadas por corpos d'água. Este índice foi criado a partir da divisão da área classificada como hidrografia no mapeamento do PRODES pela área total da cena, denominado Índice de Hidrografia da Cena (IH).

\section{DADOS DE UNIDADES DE CONSERVAÇÃO}

A literatura mostra a importância do Sistema Nacional de Unidades de Conservação (SNUC) na conservação de recursos naturais e da biodiversidade (Ferreira et al., 2005; Teixeira, 2005). Estas unidades de conservação, além de restringir o uso da terra nas áreas onde são estabelecidas, podem influenciar no processo de formação de vegetação secundária. A criação de Unidades de Conservação pode trazer um impacto imediato em seu entorno, diminuindo o estoque de terras disponíveis para as atividades agropecuárias que, desta maneira, passam a sofrer maior pressão. Assim, foi criado um índice que expressa o quanto da área total da cena é ocupada por Unidade de Conservação, nos níveis estadual e federal, além das terras indígenas. Este índice, denominado de Índice de Unidade de Conservação (IUC), é formado pela razão entre a área total ocupada por Unidades de Conservação (UC's), dividido pela área total da cena. Os dados de Unidade de Conservação foram fornecidos pelo Centro de Sensoriamento Remoto do IBAMA (IBAMA, 2008).

\section{MÉTODOS}

A metodologia adotada para estimar vegetação secundária na AML baseou-se na geração de um conjunto amostral estratificado de mapas de vegetação secundária nas áreas desflorestadas em 2006 da AML, apontadas pelo Prodes.
Para a geração desses mapas foram utilizadas imagens TM/ Landsat e técnicas de processamento imagens. Um modelo estatístico multilinear foi construído considerando como variável dependente a área de vegetação secundária das cenas. As variáveis independentes foram obtidas a partir de dados de Unidades de Conservação, hidrografia, ecorregióes, concentração fundiária e desflorestamento.

Os procedimentos podem ser agrupados em quatro etapas principais: 1) Amostragem e seleção de cenas Landsat/TM; 2) Mapeamento da vegetação secundária nas cenas amostradas; 3) Construção de indicadores como variáveis para o modelo e; 4) Construção de modelo multilinear para estimativa de vegetação secundária. Essas etapas são detalhadas nas seçóes seguintes.

\section{ESTRATIFICAÇÃO DAS CENAS LANDSAT-TM}

Para o recobrimento completo da região da AML pelo satélite Landsat/TM são necessárias 229 cenas LANDSATTM. Essas cenas foram agrupadas em sete estratos, em função da proporção de desflorestamento, seguindo o critério adotado pelo Ministério da Ciência e Tecnologia (MCT, 2004). Essa proporção é denominada Índice de Desflorestamento (ID) e foi utilizada para agrupar as cenas nos seguintes estratos: de 0 a $1 \%$, de 1 a $5 \%$, de 5 a $10 \%$, de 10 a $20 \%$, de 20 a $30 \%$, de 30 a $55 \%$ e acima de $55 \%$ de desflorestamento.

Foram consideradas como áreas desflorestadas aquelas que eram originalmente cobertas por alguma formação vegetal de fisionomia florestal e que foram suprimidas em algum momento. Neste projeto, foi considerada como área originalmente do tipo florestal, o somatório das áreas apontadas pelo PRODES como pertencentes à classe temática floresta e as áreas apontadas pelo PRODES como desflorestadas.

Para estimar o Índice de Desflorestamento, foram analisados os dados publicados pelo PRODES para o ano de 2006, calculando a razão entre a área desflorestada pela área original de floresta de cada cena, conforme na Equação (4.1) a seguir:

$$
\mathrm{ID}=\mathrm{AD} / \mathrm{AFO}
$$

Onde ID é o Índice de desflorestamento, AD é a área desflorestada e AFO é a área de floresta original da cena, segundo o levantamento do PRODES de 2006.

\section{AMOSTRAGEM DAS CENAS}

O tamanho de amostra $\left(\mathbf{n}_{0}\right)$ foi calculado com base em Cochran (1977) conforme a Equação (4.2):

$$
\mathrm{n}_{0}=\left(\mathrm{t}_{\mathrm{x} 2}\right)^{2}(\mathrm{CV} \%)^{2} /(\mathrm{D} \%)^{2}
$$

Onde $\mathrm{D} \%$ é a semi-amplitude do intervalo de confiança que neste estudo foi definido em 5\%; $\mathrm{t}_{\mathrm{x} 2}$ é o valor de $\mathrm{t}$ de 
Student para o nível de confiança da inferência (95\%) e; CV\% é o coeficiente de variaçáo

O resultado final de $\mathrm{n}_{0}$ foi calculado em $\mathrm{km}^{2}$. Foram utilizadas as cenas LANDSAT-TM como unidade amostral, que têm uma área média de pouco mais de $21.000 \mathrm{~km}^{2}$. Considerando este valor, supôs-se que cada $21.000 \mathrm{~km}^{2}$ seria considerado como uma nova cena a ser mapeada. Não foram trabalhadas fraçôes de imagens, toda fração foi arredondada para o próximo valor inteiro.

Antes de efetuar o sorteio aleatório que definiu quais cenas seriam utilizadas no presente estudo, foram excluídas as cenas que tinham menos de $2.000 \mathrm{~km}^{2}$ de floresta original, e também as com menos de $100 \mathrm{~km}^{2}$ desflorestados em 2006 . A exclusão teve por objetivo evitar a utilização de cenas com área original de floresta muito pequena e/ou muito pouco desflorestadas.

\section{MAPEAMENTO DA VEGETACÃO SECUNDÁRIA NAS CENAS AMOSTRADAS}

\section{CONSTRUÇÃO DO BANCO DE DADOS}

Um bancos de dados geográfico foi montado contendo os mosaicos de imagens Landsat/TM ortorretificadas Geocover (NASA, 2008) e os dados temáticos utilizados para caracterização de cada uma das cenas amostradas. $\mathrm{O}$ Geocover foi avaliado por Albuquerque e Medeiros (2004), que encontraram uma qualidade planimétrica compatível com as especificaçóes para a escala de 1:100.000.

As cenas selecionadas foram georreferenciadas para que os dados que seriam incorporados ao banco tivessem um posicionamento que permitisse a superposição das imagens de diferentes datas e também em relação aos dados temáticos. A base de referência utilizada no projeto PRODES é o mosaico ortorretificado de imagens LANDSAT TM-5 (NASA, 2008).

\section{MAPEAMENTO DA VEGETAÇÃO SECUNDÁRIA}

Durante esta fase foram realizados os procedimentos de classificação de imagens para a geraçáo dos mapas de vegetaçáo secundária. A técnica utilizada para o mapeamento da vegetação secundária foi um modelo linear de mistura espectral para a geração de imagens fração. De acordo com Shimabukuro e Smith (1991) a resposta de cada pixel é uma combinação linear da resposta espectral dos componentes Solo, Sombra e Vegetaçáo existentes na superfície terrestre. $\mathrm{O}$ modelo linear de mistura espectral possibilita estimar a proporçấo desses componentes para cada pixel, produzindo imagens de cada um dos componentes puros. Esta técnica tem como principal vantagem, a redução da dimensionalidade dos dados e realce de alguns alvos de interesse, sendo útil principalmente em áreas extensas (Aguiar e Shimabukuro, 1999).

Visando minimizar o tempo de processamento das imagens e aumentar a eficácia no mapeamento da vegetaçáo secundária, as imagens fração geradas para cada uma das cenas amostradas, foram recortadas de acordo com o mapeamento do PRODES. Foram utilizadas máscaras de floresta do PRODES de forma que as imagens fração recortadas contivessem apenas para as áreas desflorestadas até 2006.

A classificação das imagens foi realizada a partir de operaçôes de fatiamento a partir do valor do nível de cinza das imagem fração, que possibilitaram identificar e separar o conjunto de pixels onde havia vegetação secundária nas imagens recortadas da fração solo ou vegetação. Utilizando a composição colorida das bandas 3, 4 e 5 do LANDSATTM5 foram identificadas, por meio de interpretação visual, as regiôes que apresentavam vegetação secundária. Os intervalos para o fatiamento foram definidos a partir de valores de nível de cinza que correspondiam a essa cobertura vegetal. Conforme pode ser encontrado em Shimabukuro e Smith (1991); Hall et al., (1995); Bernardes (1998); Roberts et al. (2002); Lu et al. (2003b, 2004a, 2004b); as área ocupadas por formaçóes florestadas (ainda que em regeneração inicial) apresentam valores de nível de cinza expressivamente maiores que as áreas desflorestadas na imagem fração vegetação e, valores menores na fração solo.

Para locais onde há agricultura, a fração sombra ajudou a dirimir as dúvidas visto que nestas áreas o valor do nível de cinza é maior para os locais com vegetação do tipo florestal do que para as áreas de agricultura, devido a uma maior heterogeneidade no dossel florestal, que causa um maior sombreamento.

As imagens classificadas resultante do fatiamento e contendo as áreas com vegetação secundária, foram avaliadas tendo por base a composição colorida R5 G4 B3, e, quando necessário, foram editadas, obtendo-se como resultado final, mapas de vegetação secundária relativos a cada cena.

\section{AVALIAÇÃO DA CLASSIFICAÇÃO COM DADOS DE CAMPO}

Através de visita ao campo em pontos previamente selecionados, foi possível verificar "in loco" a consistência do mapeamento realizado. A seleção dos locais a serem visitados buscou cobrir a maior área possível para avaliar o mapeamento sob diversas condiçóes. Para avaliação do mapeamento com dados de campo foi utilizada uma matriz de confusão, onde foram registrados os índices de acertos e os falsos positivos, ou seja, áreas que foram classificadas como vegetação secundária, mas que pertenciam a outra classe de cobertura da terra. Devido a grande extensão da área, não foi possível avaliar o índice de falsos negativos, ou seja, áreas não classificadas como vegetação secundária mas que apresentavam essa cobertura vegetal.

O trabalho de campo foi realizado durante 46 dias por via terrestre a partir de um roteiro com pontos pré-estabelecidos no qual foram percorridos mais de $15.000 \mathrm{~km}$. Foram 
visitados 355 pontos mapeados como vegetação secundária. Nos pontos checados foi registrada a ocorrência de vegetação secundária, foi coletado um ponto com GPS e realizado registro fotográfico do local.

\section{CONSTRUÇÃO DOS INDICADORES}

Nessa sessão são apresentados os indicadores utilizados como variáveis no modelo de regressão multilinear. São também descritas as operaçóes executadas para a construção dos indicadores e a justificativa para seu uso no modelo.

\section{CÁLCULO DO ÍNDICE DE VEGETAÇÃO SECUNDÁRIA MAPEADA (IVSM)}

Após o mapeamento da vegetação secundária, foi calculado o Índice de Vegetação Secundária Mapeada (IVSM) de cada cena. Para chegar ao IVSM foi dividido o valor da área mapeada de vegetação secundária, pela área total desflorestada da mesma cena, obtendo-se assim um índice que mostra qual porcentagem da área desflorestada que estava coberta por vegetação secundária. Este índice foi usado como variável dependente.

\section{ÍNDICE DE DESFLORESTAMENTO (ID/LID)}

Este índice foi utilizado para verificar a influência do desmatamento na formação de vegetação secundária. De acordo com os resultados obtidos por Alves e Skole (1996) e Alves et al. (2003) em Rondônia, as áreas que apresentam maior área desflorestada apresentam também menores taxas de formação de vegetação secundária. $\mathrm{O}$ índice de desflorestamento (ID) de cada uma das cenas foi estimado através da divisão do valor da área desflorestada de cada cena pela sua área total, como indicado na equação 4.1. Ao avaliar a correlação do índice de desflorestamento (ID) com o índice de vegetação secundária mapeada (IVSM) observou-se que esta poderia ser melhorada com a aplicação de uma transformação logarítmica na variável ID, obtendo-se o Logaritmo do Índice de Desflorestamento (LID), que apresentou uma correlação mais significativa com o IVSM.

\section{ÍNDICE DE HIDROGRAFIA DA CENA}

$\mathrm{O}$ índice de hidrografia (IH) é um indicador que busca representar as áreas de ocupação ribeirinha, onde predominam as formas mais tradicionais de uso da terra como a agricultura itinerante ( Perz e Skole; 2003) e, tende a apresentar maior extensão de vegetação secundária devido ao abandono de áreas para a recuperação da fertilidade do solo.

Nos mapas do PRODES, além das áreas desflorestadas nos respectivos anos, dados de hidrografia são mapeados a partir das cenas LANDSAT-TM5. Utilizando este mapeamento de hidrografia foi criado o Índice de Hidrografia da cena (IH) dividindo-se o valor total da área ocupada por hidrografia, pelo valor total da área dessa mesma cena. $\mathrm{O} \mathrm{IH}$ mostra o quanto da área total da cena em estudo é ocupada por corpos de água (Rios, lagos, reservatórios e áreas inundadas).

\section{ÍNDICE UNIDADE DE CONSERVAÇÃO DA CENA (IUC)}

As Unidades de Conservação podem influenciar no processo de formação de vegetação secundária, diminuindo o estoque de terras disponíveis para as atividades agropecuárias e exercendo maior pressão de uso, podendo levar a uma diminuição na formação dessa vegetação. $O$ índice definido para representar essa variável foi obtido a partir dos dados contidos no mapa de unidades de conservação fornecido pelo IBAMA (IBAMA, 2008). Esse índice representa o quanto de área de conservação existe em cada uma das cenas avaliadas. Este índice foi criado através da divisão do valor do somatório das áreas de conservação (descontada a duplicidade de áreas entre unidades de conservação) pelo valor da área total da cena.

\section{CÁLCULO DO ÍNDICE DE ECORREGIÃO FLORESTADA (IEF)}

As ecorregiōes propostas por Olsen (2001) foram utilizadas para representar o ambiente físico da AML. Foram sobrepostos os mapas temáticos de áreas desflorestadas apontadas pelo PRODES e os dados de Ecorregióes de maneira a obter-se os valores por cena para cada uma das classes de ecorregióes. Os resultados foram agrupados em áreas desflorestadas em ecorregióes do tipo florestal e áreas desflorestadas em ecorregiôes do tipo não florestal. Em seguida, o valor das áreas desflorestadas e em ecorregióes do tipo florestal foi dividido pela área desflorestada total da cena, obtendo-se, assim, o IEF de cada cena.

\section{CÁLCULO DO ÍNDICE DE BAIXA CONCENTRAÇÃO AGRÁRIA (IBCA)}

Esse índice foi proposto para verificar a influência da estrutura agrária na formação de vegetação secundária. Segundo os estudos de D'antona et al. (2006) propriedades menores tendem a apresentar florestas secundárias com ciclos mais curtos devido à escassez de terra, mantendo a área em constante utilizaçáo agrícola e impedindo a formação de vegetaçáo secundária intermediária ou avançada.

A variável foi obtida a partir do Mapa de Estrutura Agrária da AML (IBGE, 2007) e dos dados de desflorestamento do PRODES. Através de uma operação de tabulação cruzada, foram sobrepostos os mapas temáticos de áreas desflorestadas apontadas pelo PRODES e as áreas de baixa concentração agrária extraída do Mapa de Estrutura Agrária . Em seguida o valor das áreas desflorestadas e com baixa concentração agrária foi dividido pela área desflorestada total da cena obtendo-se, assim, o IBCA de cada cena.

\section{CONSTRUÇÃO DO MODELO DE REGRESSÃO MULTILINEAR}

A avaliação de alteraçóes em uma variável dependente, a partir de outras variáveis independentes é conhecida por regressão linear múltipla (Spiegel, 1977). 
Usando os valores calculados para a variável dependente IVSM e para as variáveis independentes IH, IEF, IBCA, LID e IUC, construiu-se um modelo de regressão que analisou a influência de cada um dos índices na formação de vegetação secundária a partir de uma equação preditiva capaz de estimar qual percentual da área desflorestada de cada cena estava ocupada por vegetação secundária no ano de 2006.

\section{MODELO PARA ESTIMATIVA DA VEGETAÇÃO SECUNDÁRIA.}

$\mathrm{O}$ modelo geral de construção da equação de regressão linear está disposto na Equação adaptada de Neter e Wasserman (1974) conforme a Equação (4.3) seguir:

$$
\mathrm{Y}_{\mathrm{i}}=\beta_{0}+\beta_{1} \mathrm{X}_{1}+\beta_{2} \mathrm{X}_{2}+\ldots+\beta_{\mathrm{p}} \mathrm{X}_{\mathrm{ip}}+\mathrm{E}_{\mathrm{i}}(\mathrm{i}=1, \ldots, \mathrm{n}) \text {. (4.3) }
$$

A partir da Equaçáo do modelo construído, e utilizando os valores identificados para as variáveis independentes, foi calculada a estimativa da vegetaçáo secundária para todas as cenas da Amazônia Legal, excetuando-se as cenas que apresentavam valor de desflorestamento igual a zero, onde não existe vegetação secundária.

\section{TESTE DA ESTABILIDADE DO MODELO.}

Para testar a estabilidade da composiçáo do modelo, foi realizado um teste de validaçáo cruzada, que consistiu em retirar individualmente cada uma das cenas e, com os valores dos índices das cenas restantes, construir novos modelos. Ao final, os valores encontrados para os coeficientes foram avaliados de maneira a diagnosticar se alguma das cenas apresentava influência muito forte na construção do modelo.

\section{CÁLCULO DA INCERTEZA DA ESTIMATIVA.}

A incerteza do modelo foi avaliada a partir da variância das prediçôes de vegetação secundária. A estimativa da variância das prediçóes foram calculadas a partir da Equação (4.4) adaptada de Neter e Wasserman (1974), para as 26 cenas que foram amostradas:

$$
s^{2}\left(\hat{Y}_{h}\right)=\operatorname{MSE}\left(\mathrm{X}_{\mathrm{h}}^{\prime}\left(\mathrm{X}^{\prime} \mathrm{X}\right)^{-1} \mathrm{X}_{\mathrm{h}}\right)
$$

Para as outras cenas que não entraram na amostragem, a estimativa da variância do valor estimado $-s^{2}\left(\hat{Y}_{h}\right)-$ foi obtida pela seguinte Equação (4.5) (NETER; WASSERMAN, 1974):

$$
s^{2}\left(\hat{Y}_{h}\right)=\operatorname{MSE}\left(1+X_{h}^{\prime}\left(X^{\prime} X\right)^{-1} X_{h}\right)
$$

Depois de efetuado o calculo da estimativa de vegetação secundária para cada uma das cenas da AML e calculadas as suas respectivas variâncias, foi possível identificar o desvio padráo de cada uma cenas. Assumindo a completa independência das prediçôes, a estimativa da incerteza total foi obtida pelo somatório do desvio padrão de cada uma das estimativas.

A estimativa da incerteza total, como descrita anteriormente, pressupóem considerar todas as possibilidades, como por exemplo, que todas as estimativas sejam calculadas pelo menor desvio padráo, ou, o contrário, que todas as estimativas sejam calculadas pelo maior valor do desvio padráo. Aceitando-se que as prediçóes variam de forma normal, as estimativas dos desvios padróes devem estar próximas aos valores médios.

Outra maneira de estabelecer um intervalo de credibilidade é através do uso da ferramenta de simulação Monte Carlo, que consiste em conduzir experimentos múltiplas vezes para simular um sistema real, através da teoria das grandes amostras. Com a conduçáo simulaçóes de Monte Carlo em uma quantidade suficiente para se encontrar o ponto de equilíbrio da curva de respostas, pode-se calcular os valores estimados, e estimar um novo intervalo de credibilidade, composto do intervalo entre o menor e o maior valor estimado, para o somatório dos desvios padróes.

\section{RESULTADOS E DISCUSSÕES}

\section{AMOSTRAGEM}

Das 229 cenas da AML, foram selecionadas 26 para o mapeamento de vegetação secundária, considerando o grau de desflorestamento e os sete estratos propostos. Este resultado está apresentado na Tabela 1.

\section{MAPEAMENTO DA VEGETAÇÃO SECUNDÁRIA}

Os resultados para os índices analisados, obtidos a partir do mapeamento da vegetaçáo secundária, encontram-se na Tabela 2. A tabela mostra para cada cena o índice de desflorestamento

Tabela.1 -Número de imagens selecionadas por grau de desflorestamento

\begin{tabular}{lcc}
\hline $\begin{array}{l}\text { Desflorestamento } \\
\text { da cena }\end{array}$ & $\begin{array}{c}\text { Número de } \\
\text { cenas no estrato }\end{array}$ & $\begin{array}{c}\text { Número de } \\
\text { Amostras }\end{array}$ \\
\hline 0 a 1\% & 71 & 3 \\
1 a $5 \%$ & 47 & 4 \\
\hline 5 a $10 \%$ & 17 & 3 \\
10 a $20 \%$ & 22 & 4 \\
20 a $30 \%$ & 16 & 4 \\
30 a $55 \%$ & 23 & 3 \\
> 55\% & 33 & 5 \\
Total & & 26 \\
\hline
\end{tabular}

(ID), as áreas totais de vegetação secundária mapeada (VSM) em $\mathrm{km}^{2}$ e o índice de vegetaçấo secundária mapeada (IVSM). O IVSM normalizou a área de vegetação secundária mapeada em função da área total desflorestada em cada cena. $\mathrm{O}$ valor desse índice variou entre 0 e 1 , onde 0 representa ausência de vegetação secundária na área desflorestada da cena, e 1 representa a regeneração de toda a área desflorestada.

A análise da Tabela 2 indica que a medida que o Índice de Desflorestamento (ID) aumenta, há uma queda no Índice de Vegetação Secundária Mapeada (IVSM). Esta observação 
Tabela 2 - Área de vegetação secundária obtida a partir do mapeamento das cenas.

\begin{tabular}{lccc}
\hline Cena & ID & VSM 2006 & IVSM \\
\hline 23362 & 0,0044 & 95,55 & 0,8134 \\
\hline 23358 & 0,0045 & 73,89 & 0,5479 \\
\hline 00264 & 0,0052 & 120,46 & 0,8391 \\
\hline 22566 & 0,0108 & 55,74 & 0,2129 \\
\hline 00367 & 0,0192 & 221,20 & 0,3962 \\
\hline 22961 & 0,0234 & 235,75 & 0,3723 \\
\hline 23368 & 0,0416 & 106,72 & 0,4444 \\
\hline 00565 & 0,0668 & 758,51 & 0,3895 \\
\hline 00266 & 0,0735 & 539,25 & 0,2622 \\
\hline 22672 & 0,0977 & 66,63 & 0,2763 \\
\hline 22368 & 0,1321 & 49,27 & 0,1084 \\
\hline 22863 & 0,1559 & 2068,09 & 0,4782 \\
\hline 23266 & 0,1857 & 1451,36 & 0,2952 \\
\hline 22968 & 0,1909 & 556,92 & 0,1217 \\
\hline 22962 & 0,2022 & 2358,00 & 0,7258 \\
\hline 23258 & 0,2229 & 931,87 & 0,2878 \\
\hline 22567 & 0,2312 & 627,93 & 0,1138 \\
\hline 23367 & 0,2768 & 1003,41 & 0,1959 \\
\hline 23068 & 0,4049 & 1162,09 & 0,1128 \\
\hline 22362 & 0,4572 & 3412,26 & 0,2660 \\
\hline 22870 & 0,5286 & 514,37 & 0,1097 \\
\hline 22467 & 0,5593 & 1910,09 & 0,1382 \\
\hline 22363 & 0,5976 & 3454,68 & 0,2087 \\
\hline 22064 & 0,6302 & 882,56 & 0,1728 \\
\hline 22670 & 0,6481 & 269,78 & 0,0878 \\
\hline 22770 & 0,6499 & 1194,09 & 0,1275 \\
\hline & & & \\
\hline
\end{tabular}

corrobora com os resultados obtidos por Alves et al. (2003), sugerindo que o aumento da área desflorestada leva à intensificaçáo de uso da terra, diminuindo proporcionalmente a formação de vegetação secundária.

Importante notar que o IVSM apresenta alguns valores acima ou abaixo do esperado. Tais variaçóes podem ser explicadas pela presença ou ausência de outras características nas cenas, como por exemplo, unidades de conservaçáo, presença e tamanho de corpos d água e tamanho das propriedades. A influência de cada uma destas características será apresentada pelo modelo de regressão multilinear.

\section{VALIDAÇÃO DE CAMPO.}

$\mathrm{Na}$ vistoria de campo foi verificada a ocorrência de vegetação secundária nas área mapeadas possibilitando registrar os acertos e erros em função da ocorrência ou ausência desta cobertura nos pontos indicados.

Os resultados da campanha de campo mostraram um alto grau de acerto $(92,11 \%)$ da técnica de mapeamento. No total foram visitados 355 pontos, sendo que destes 28
(7,89\%) foram considerados erros de classificação. Desse total, 4 pontos corresponderam as áreas de reflorestamento, 4 corresponderam as áreas de pastagem, 4 corresponderam as áreas de agricultura perene arbórea e em 16 pontos foram observadas diferenças quanto à área e/ou forma mapeada em comparação ao encontrado em campo. Esta comparaçáo foi feita de forma estritamente visual. Os 327 pontos restantes $(92,11 \%)$ foram considerados como acerto do mapeamento.

\section{ESTIMATIVA DA ÁREA DE VEGETAÇÃO SECUNDÁRIA.}

Foram examinadas as relações entre o Índice de Vegetação Secundária Mapeada -IVSM (variável dependente) e as cinco variáveis independentes. A Tabela 3 mostra os valores encontrados para cada uma das variáveis em cada uma das 26 cenas analisadas neste estudo.

Para a escolha das variáveis que participariam do modelo de regressão multilinear foram utilizados os métodos de Forward Stepwise e Backward Stepwise com um P de 0,050. Em ambos os testes chegou-se ao mesmo conjunto de variáveis selecionadas. As variáveis selecionadas para a construçáo do

Tabela.3- Valores das variáveis para cada uma das cenas

\begin{tabular}{lllllll}
\hline Cena & LID & IH & IUC & IEF & IBCA & IVSM \\
\hline 00264 & $-2,282$ & 0,0124 & 0,4470 & 0,820 & 0,727 & 0,629 \\
\hline 00266 & $-1,134$ & 0,0055 & 0,4500 & 0,701 & 0,043 & 0,262 \\
\hline 00367 & $-1,717$ & 0,0002 & 0,7700 & 0,980 & 0,119 & 0,396 \\
\hline 00565 & $-1,175$ & 0,0008 & 0,4671 & 0,419 & 0,000 & 0,389 \\
\hline 22064 & $-0,200$ & 0,0041 & 0,0600 & 0,727 & 0,000 & 0,172 \\
\hline 22362 & $-0,340$ & 0,0028 & 0,0100 & 1,000 & 0,062 & 0,266 \\
\hline 22363 & $-0,224$ & 0,0054 & 0,0300 & 0,999 & 0,000 & 0,209 \\
\hline 22368 & $-0,880$ & 0,0133 & 0,4900 & 0,000 & 0,000 & 0,108 \\
\hline 22467 & $-0,252$ & 0,0002 & 0,0700 & 0,884 & 0,000 & 0,138 \\
\hline 22566 & $-1,965$ & 0,0113 & 0,9600 & 1,000 & 0,000 & 0,213 \\
\hline 22567 & $-0,636$ & 0,0106 & 0,5000 & 1,000 & 0,000 & 0,113 \\
22670 & $-0,188$ & 0,0085 & 0,2100 & 0,000 & 0,000 & 0,088 \\
\hline 22672 & $-1,010$ & 0,0056 & 0,0200 & 0,000 & 0,000 & 0,276 \\
\hline 22770 & $-0,187$ & 0,0003 & 0,0100 & 0,803 & 0,000 & 0,128 \\
\hline 22863 & $-0,807$ & 0,0255 & 0,5000 & 1,000 & 1,000 & 0,478 \\
\hline 22870 & $-0,277$ & 0,0001 & 0,3200 & 0,882 & 0,000 & 0,110 \\
\hline 22961 & $-1,630$ & 0,0332 & 0,6700 & 0,818 & 0,269 & 0,372 \\
\hline 22962 & $-0,694$ & 0,2232 & 0,1400 & 0,898 & 0,241 & 0,725 \\
\hline 22968 & $-0,719$ & 0,0002 & 0,6500 & 0,933 & 0,000 & 0,122 \\
\hline 23068 & $-0,393$ & 0,0005 & 0,3600 & 0,994 & 0,000 & 0,113 \\
\hline 23258 & $-0,651$ & 0,0089 & 0,1800 & 0,356 & 0,445 & 0,288 \\
\hline 23266 & $-0,731$ & 0,0380 & 0,5000 & 0,814 & 0,159 & 0,295 \\
\hline 23358 & $-2,347$ & 0,0047 & 0,8518 & 0,595 & 0,217 & 0,548 \\
\hline 23362 & $-2,353$ & 0,0448 & 0,5106 & 0,601 & 0,360 & 0,813 \\
\hline 23367 & $-0,558$ & 0,0104 & 0,3800 & 1,000 & 0,399 & 0,196 \\
23368 & $-1,381$ & 0,0203 & 0,8600 & 0,886 & 0,000 & 0,444 \\
\hline & & & & & & \\
\hline
\end{tabular}


modelo foram o Logaritmo do Índice de Desflorestamento (LID), o Índice de Hidrografia da Cena (IH), o Índice de Baixa Concentração Agrária (IBCA) e o Índice de Unidade de Conservação da Cena (IUC). A variável Índice de Ecorregiốes Florestadas (IEF) não apresentou relação significativa com a variável dependente IVSM. O modelo resultante da análise é apresentado na Tabela 4.

Com base na equação de regressão resultante foi estimado o IVSM para todas as cenas que recobrem a AML. O IVSM mostra o grau de formação de vegetação secundária nas

Tabela 4 - Parâmetros do modelo de regressão linear

\begin{tabular}{|c|c|c|c|c|}
\hline \multicolumn{5}{|c|}{ Sumario } \\
\hline $\mathrm{R}^{2}$ & $\mathrm{R}$ & $\mathrm{R}^{2}$ Aust. & \multicolumn{2}{|c|}{ Erro Médio } \\
\hline 0,869 & 0,932 & 0,844 & \multicolumn{2}{|c|}{0,079} \\
\hline \multicolumn{5}{|l|}{ ANOVA } \\
\hline Fonte & S.Q & G.L.. & $\begin{array}{l}\text { Quad. } \\
\text { Médio }\end{array}$ & $\mathrm{F}$ \\
\hline Regressão & 0,879 & 4 & 0,220 & 34,806 \\
\hline Residuo & 0,133 & 21 & 0,006 & \\
\hline Total & 1,011 & 25 & & \\
\hline \multicolumn{5}{|c|}{ Coeficientes de Regressão } \\
\hline Fonte & Coeficiente & Erro Padrão & Valor $\mathrm{P}$ & \\
\hline Intercept & 0,102 & 0,030 & & \\
\hline IBCA & 0,197 & 0,068 & 0,248 & \\
\hline LID & $-0,232$ & 0,035 & $-0,813$ & \\
\hline $\mathrm{IH}$ & 2,055 & 0,377 & 0,444 & \\
\hline IUC & $-0,219$ & 0,082 & $-0,310$ & \\
\hline
\end{tabular}

áreas desflorestadas das cenas. Para traduzir este índice em valores estimados de área de vegetação secundária por cena foi preciso transformar este número relativo em número absoluto. Esta transformação foi feita através de uma inversão da proporção estimada, a partir dos dados de desflorestamento das cenas. Assim, multiplicando o IVSM pela área total desflorestada de uma cena específica, obtevese o valor absoluto de vegetação secundária para a cena em questáo. Replicando esta operação para todas as cenas da AML, chegou-se a estimativa de ocorrência de vegetação secundária para a AML.

Como resultado da estimativa de ocorrência de vegetação secundária chegou-se a um valor total estimado de $131.873 \mathrm{~km}^{2}$ de vegetação secundária na AML para o ano de 2006. Das 229 cenas que recobrem a $\mathrm{AML}$, não foi estimada a vegetação secundária em 16 cenas, ou por não apresentarem área de desflorestamento, ou por não apresentarem área de formação florestal. A Tabela 5 mostra o valor estimado de vegetaçáo secundária totalizado pelos estratos da amostragem.
Com relaçáo ao Índice de Baixa Concentração Agrária (IBCA), que expressa o quanto da área estudada está em posse de pequenos proprietários, encontrou-se uma relação positiva

Tabela 5 - Distribuição da estimativa de vegetação secundária por estrato

\begin{tabular}{lccc}
\hline Estrato & No Cenas & $\begin{array}{c}\text { Estimativa Estrato } \\
\left(\mathrm{Km}^{2}\right)\end{array}$ & $\begin{array}{c}\text { \% Veg. Sec. } \\
\text { Estimada }\end{array}$ \\
\hline $0-1 \%$ & 71 & 2448,14 & $1,86 \%$ \\
$1-5 \%$ & 47 & 10535,02 & $7,99 \%$ \\
$5-10 \%$ & 17 & 8313,77 & $6,30 \%$ \\
\hline $10-20 \%$ & 22 & 19529,49 & $14,81 \%$ \\
$20-30 \%$ & 16 & 21735,16 & $16,48 \%$ \\
$30-55 \%$ & 23 & 29058,46 & $22,04 \%$ \\
$>55 \%$ & 33 & 40253,24 & $30,52 \%$ \\
Total & 213 & 131873,29 & $100,00 \%$ \\
\hline
\end{tabular}

com o IVSM. Desta maneira, conclui-se que em áreas onde há uma maior presença de pequenos produtores rurais há uma maior ocorrência de vegetação secundária.

Este resultado difere dos encontrados por D'Antona et al. (2006), que observou que pequenos proprietários mantinham parcelas maiores de suas propriedades em uso, com menores ciclos de recuperação da fertilidade do solo devido à escassez de terra. Os autores deste estudo alertam, porém, para a impossibilidade de extrapolar estes dados para regióes onde a pecuária é mais comum. Os resultado obtidos neste trabalho estáo de acordo com os obtidos por Perz e Skole (2003) que sustentam que a agricultura tradicional desenvolvida pelos pequenos proprietários influi positivamente na formação de vegetação secundária.

O Logaritmo do Índice de Desflorestamento apresentou relação negativa com o Índice de Vegetação Secundária Mapeada (IVSM). Para entender espacialmente como o LID e o IVSM se relacionam foram criadas figuras que mostram o IVSM na AML e foi feita uma transformaçáo deste índice em números absolutos para conhecer a real distribuição da vegetação secundária em $\mathrm{km}^{2}$, ao longo da $\mathrm{AML}$.

As Figuras 2 e 3 mostram respectivamente a distribuição da estimativa do IVSM e a distribuição da estimativa de vegetaçâo secundária em todas as cenas da AML. Essas representações foram obtidas através da criação de uma superfície com modelo numérico de terreno do SPRING, e a imagem visualizada é uma representação desta grade regular, tendo como valor z a estimativa do Índice de Vegetação Secundária Mapeada (IVSM) e a estimativa de ocorrência de vegetação secundária $\mathrm{em} \mathrm{km}^{2}$, respectivamente. Nestas imagens o nível de cinza 0 foi associado ao menor valor de z e o nível de cinza 255 foi associado ao maior valor de z. Assim, na Figura 2, valores mais claros significam maiores IVSM e na Figura 3 
valores mais claros significam maiores estimativa em $\mathrm{km}^{2} \mathrm{de}$ vegetação secundária

A Figura 2 mostra a distribuição do IVSM estimado, que é maior nas regióes pouco desflorestadas, como o noroeste

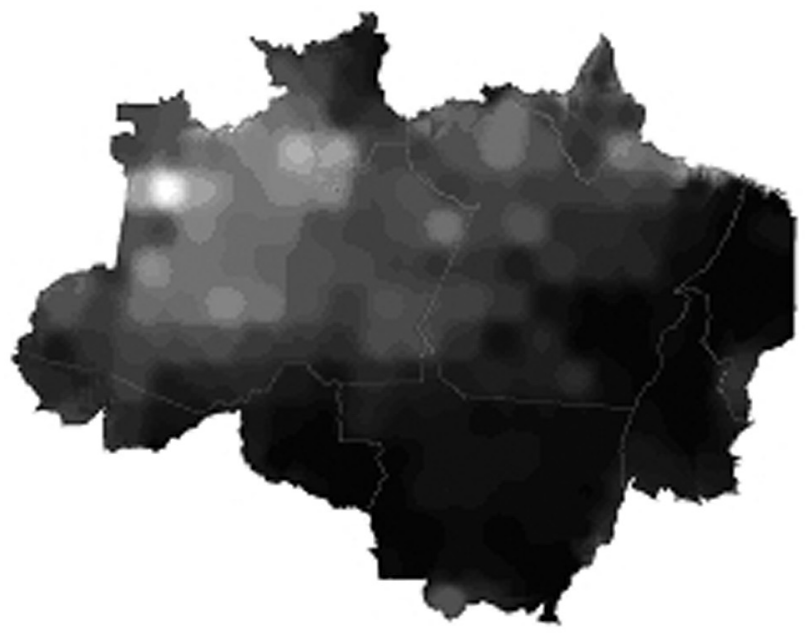

Figura 2 - Distribuição do IVSM na AML

do Amazonas. As áreas com maior desflorestamento como a regiāo denominada "arco do desflorestamento", que abrange o Maranhão, leste do Pará, norte do Mato Grosso, Rondônia e leste do Acre, apresentaram valores baixos de IVSM. Esse resultado é consistente com aqueles encontrados na literatura ( Alves e Skole 1996; Alvez, 2003; Alves, 2007; ) em escala local, evidenciando que a medida que a ocupaçáo de uma regiáo se consolida e que o desmatamento e o uso da terra se intensificam, o abandono da terra e a conseqüente formaçáo de vegetaçáo secundária diminuem. As regióes que apresentam menor proporção de vegetação secundária são aquelas que apresentam cadeias produtivas como as da pecuária ( Escada et al., 2005; Piketty et al., 2005; Américo et al., 2008) e de grãos (Mueller e Bustamente, 2002), melhor estruturadas que as demais.

A Figura 3 apresenta a distribuição espacial da vegetação secundária em termos de sua área $\left(\mathrm{em} \mathrm{km}^{2}\right)$ na AML. Nesta figura é possível observar que uma grande área de ocorrência da vegetação secundária se dá na regiáo do "arco do desflorestamento", embora a proporção da vegetação secundária em relação a área desflorestada seja menor, como observado na figura 2. Isso se dá devido à maior extensão de área desflorestadas nessa região. Outra região que apresenta grande área de ocorrência de vegetaçấo secundária é a calha do médio e baixo Amazonas. Esse padrão pode ser explicado devido ao tipo de ocupaçáo da regiâo por uma população ribeirinha, praticante de uma agricultura de subsistência e itinerante, que tem influência positiva na ocorrência de vegetação secundária ( Perz e Skole, 2003; Martins, 2005).

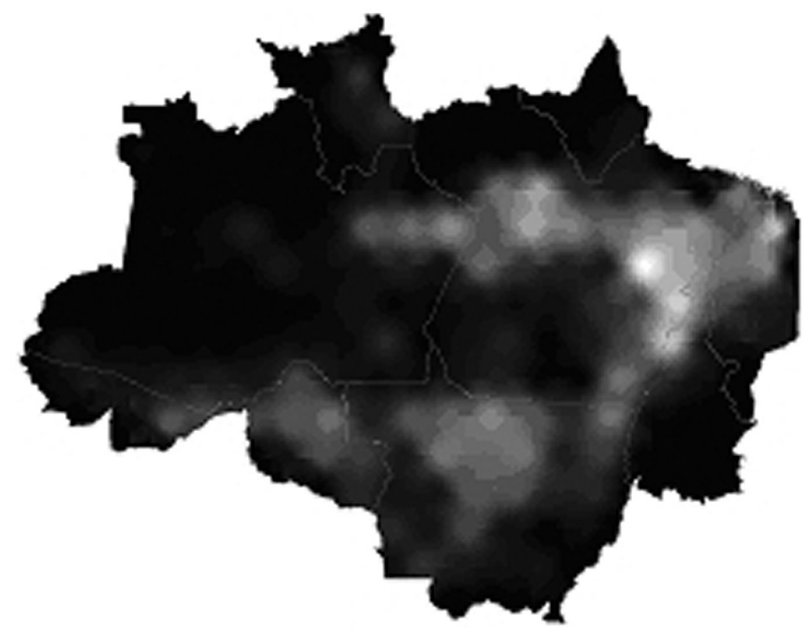

Figura 3 - Distribuição da estimativa de vegetação secundária na AML em km²

\section{CÁLCULO DA INCERTEZA DA ESTIMATIVA DA VEGETAÇÃO SECUNDÁRIA}

Conforme discutido no item 5.4 há uma incerteza nessa estimativa devido à sua variância. Usando a soma dos desvios padróes, chegou-se a uma incerteza de $0,84 \%$ para as 26 cenas que compóem a amostra e de $18,10 \%$ paras as cenas em que o modelo preditivo foi aplicado, resultando em uma incerteza tocal de $18,94 \%$. Convertida em números absolutos tem-se uma incerteza de $24.977 \mathrm{~km}^{2}$, ou seja, a estimativa de vegetação secundária estaria entre 106.896 e 156.850 km².

Outra maneira de estimar a incerteza foi empregada utilizando a simulação de Monte Carlo. Foram feitos 4 exercícios de simulação, sendo o primeiro com 1.000 simulaçôes, o segundo com 5.000 simulaçóes, o terceiro com 10.000 simulaçôes e o quarto com 100.000 simulaçóes. Os valores encontrados nas simulaçóes são apresentados na Tabela 6.

Tabela.6 - Resultados das simulações para a estimativa de incerteza na estimativa de vegetação secundária

\begin{tabular}{lccc}
\hline $\begin{array}{l}N^{0} \text { de } \\
\text { simulações }\end{array}$ & Valor médio & Menor Valor & Maior Valor \\
\hline 1000 & 133521,62 & 120635,16 & 146552,29 \\
5000 & 133127,29 & 120863,51 & 145702,01 \\
10000 & 133037,32 & 120629,07 & 145795,09 \\
100000 & 133045,52 & 120722,49 & 145607,95 \\
\hline
\end{tabular}

Nas quatro simulaçóes o valor médio encontrado foi muito próximo do valor estimado pelo modelo de regressão multilinear $\left(131.873 \mathrm{~km}^{2}\right)$, apresentando diferenças da ordem de $1 \%$. Já os valores dos limites da incerteza da estimativa 
apresentaram-se mais próximos da média, conforme se esperava. Este resultado reforça a consistência do modelo preditivo, e conseqüentemente a confiança na sua exatidão e robustez.

Considerando a incerteza do quarto exercício de simulação (100.000 simulações) temos uma incerteza média de 12.443 $\mathrm{km}^{2}$. Como a área total desflorestada em 2006 foi de 680.312 $\mathrm{km}^{2}$ (INPE, 2008), e considerando o valor encontrado pelo modelo de regressão linear de $131.873 \mathrm{~km}^{2}$ e a incerteza média de $12.443 \mathrm{~km}^{2}$, foi encontrada uma relação na qual cerca de $19,38 \pm 1,83 \%$ da área desflorestada apresenta ocorrência de vegetação secundária para o referido ano.

O valor encontrado neste estudo difere dos valores apresentados por Neeff et al. (2006) que encontraram cerca de $161.000 \mathrm{~km}^{2}$ para o ano de 2002, Lucas et al. (2000) que estimaram $157.953 \mathrm{~km}^{2}$ em 1992 e por Carreiras et al. (2006) que estimaram $140.000 \mathrm{~km}^{2}$ em 2000.

As diferenças encontradas podem ser explicadas pelos diferentes tipos de dados, datas e metodologias utilizadas. Nos três trabalhos citados o mapeamento foi realizado para toda a AML, incluindo áreas de formaçóes do tipo Não Floresta (Savanas e Campinaranas, por exemplo), e nos trabalhos de LUCAS et al., (2000) e CARREIRAS et al., (2006) foram utilizadas imagens de baixa resolução espacial, respectivamente imagens do SPOT-Vegetation e do AVHRR-NOAA, ambas com $1 \mathrm{~km}$ de resolução.

Outra diferença bastante significativa está no método de amostragem desenvolvido neste estudo, que considera o Índice de Desflorestamento das cenas (ID). Além disso, esse trabalho incluiu um maior número de variáveis para a construção do modelo explicativo da formação de vegetação secundária.

\section{CONCLUSÕES}

A técnica de mapeamento da vegetação secundária através da geração de modelo linear de mistura espectral e fatiamento pelo valor do nível de cinza das imagens fração, foi adequado para o mapeamento da vegetação secundária, apresentando um alto índice de acerto $(92,11 \%)$, conforme pode ser observado no trabalho de validação de campo.

As variáveis testadas apresentaram significativas relaçóes com a formação de vegetação secundária, exceto a variável Índice de Ecorregião Florestada (IEF), que por sua escala de mapeamento com um nível de detalhamento muito pequeno, pode não ter sido adequado a este estudo. A variável Índice de Hidrografia (IH) e a variável Índice de Baixa Concentração Agrária (IBCA) apresentaram relação positiva com a formação de vegetação secundária, já as variáveis Índice de Unidade de Conservação (IUC) e Logaritmo do Índice de Desflorestamento (LID) apresentaram relação negativa com a formaçáo de vegetação secundária. Estas relaçóes confirmaram o que era esperado para cada uma destas variáveis, mostrando ser possível estimar a extensão da vegetação secundária para a AML, a partir de dados ambientais e sócio-econômicos.

Essas estimativas podem ser de grande contribuição para o cálculo do estoque de vegetação secundária em florestas tropicais.

\section{BIBLIOGRAFIA CITADA}

Aguiar, A. P. D.; Shimabukuro, Y. E. 1999. Use of Synthetic bands derived from mixing models in the multispectral classification of remote sensing images. International Journal of Remote Sensing, 20(4):647 - 657.

Albuquerque P. C. G.; Medeiros, J. S. 2004. Evaluation Mosaics with Landsat-TM for use in documents mapping at scales smaller than 1:50,000 INPE (in Portuguese).

Alves, D. S. 2002. Space-time dynamics of deforestation in Brazilian Amazonia. International Journal of Remote Sensing, 23(14):29032908.

Alves, D. S._2007. Scenarios of cover and land use and human dimensions in the LBA. In: EDUSP (Human Dimensions of Biosphere-Atmosphere Experiment in Amazonia). 1. São Paulo, 2007, p. 39 - 64 (in Portuguese).

Alves, D. S.; Escada, M. I. S.; Pereira, J. L. G.; Linhares, C. A. 2003. Land use intensification and abandonment in Rondônia, Brazilian Amazônia. International Journal of Remote Sensing, 24(4):899 - 903

Alves, D. S.; Skole, D. L. 1996. Characterizing land cover dynamics using multi-temporal imagery. International Journal of Remote Sensing, 17(4):835-839.

Bernardes, S. 1998. Vegetation indices and fraction values to characterize primary rain forest and succession stages in the area of influence of Tapajós national forest - Para State. Dissertação de Mestrado, Instituto Nacional de Pesquisas Espaciais, São José dos Campos, São Paulo, 117pp (in Portuguese, with abstract in English).

Brown, S.; Lugo, A. E. Tropical Secondary Forests. 1990. Journal of Tropical Ecology, 6(1):1-32.

Câmara, G.; Valeriano, D. M.; Soares, J. V.; Motta, M. 2006. Methodology for calculating the annual rate of deforestation in the Brazilian Legal Amazon. Relatório Técnico .Instituto Nacional de Pesquisas Espaciais, São José dos Campos, São Paulo, 24 pp. Disponível em: http://www.obt.inpe.br/prodes/metodologia. pdf (in Portuguese).

Carreiras, J. M. B.; Pereira, J. M. C.; Campagnolo, M. L.; Shimabukuro Y. E. 2006. Assessing the extent of agriculture/ pasture and secondary succession forest in the Brazilian Legal Amazon using SPOT VEGETATION data. Remote Sensing of Environment, 101(3):283-298.

Cochran, W. G. 1977. Sampling techniques Editora: Wiley. 3ed. 448pp.

Costa, W. M. da. 1997. The State and Territorial Policies in Brazil. Ed. Contexto. $7^{\text {a }}$ ed., 83 pp (in Portuguese). 
D’antona, A. O.; Vanwey, L. K.; Hayashi, C. M. 2006. Property size and land cover change in the Brazilian amazon. Population and Environment, 27 (5-6):373-396.

Espírito-Santo, F. D. B.; Shimabukuro, Y. E.; Kuplich, T. M. 2005. Mapping forest successional stages following deforestation in Brazilian Amazonia using multi-temporal Landsat images. International Journal of Remote Sensing, 26(3):635-642.

Fearnside, P. M. 1996. Amazonian deforestation and global warming: Carbon stocks in vegetation replacing Brazil's Amazon forest. Forest Ecology and Management.80 (1-3):21-34.

Fearnside, P. M. 2005. Deforestation in Brazilian Amazonia: History, rates, and consequences. Conservation Biology ,19( 3):680-688.

Ferreira, L. V.; Venticinque, E.; Almeida, S. O. 2005. Deforestation in the Amazon and the importance of protected areas. Estudos Avançados, 19(53):157-166 (in Portuguese, with abstract in English).

Hall, F. G.; Shimabukuro, Y. E.; Huemmrich, K. F. 1995. RemoteSensing of Forest Biophysical Structure Using Mixture Decomposition and Geometric Reflectance Models. Ecological Applications. 5(4): 993-1013.

Hurtienne, T. 2005. Family farmers and sustainable rural development in Amazon. Novos Cadernos NAEA, 8(1):019-071 (in Portuguese, with abstract in English).

IBAMA. 2006. Brasilian Ecoregions. Disponível em: http://www. ibama.gov.br/ecossistemas/ecoregioes.htm. Acesso em: 09 set 2008 (in Portuguese).

IBAMA. 2008. Map of protected areas. Disponível em: http://siscom. ibama.gov.br/shapes/. Accesso em: 20 set 2008 (in Portuguese).

IBGE. 2007. Map of ZEE of Brazilian Legal Amazon. Disponível em: ftp://geoftp.ibge.gov.br/mapas/tematicos/integrado_zee_ amazonia_legal/Amazonia_Estrutura_Agraria.pdf. Acesso em: $22 \mathrm{fev} 2007$ (in Portuguese).

INPE. 2008. Monitoring of the Brazilian Amazonian forest by satellite. Disponível em: http://www.obt.inpe.br/prodes/. Acesso em: 08 Sep 2008 (in Portuguese).

Juo, A. S. R.; Manu, A. 1996.Chemical dynamics in slash-and-burn agriculture. Agriculture Ecosystems \& Environment, 58(1):49-60.

Laurance, W. F. 1999. Reflections on the tropical deforestation crisis. Biological Conservation, 91(2-3): 109-117.

Laurance, W. F.; Albernaz, A. K. M.; Fearnside, P. M.; Vasconcelos, S. H. L.; Ferreira, L. V. 2004.Deforestation in Amazonia. Science, 304(5674):1109-1109.

Loveland, T. R.; Merchant, J. M. 2004. Ecoregions and ecoregionalization: Geographical and ecological perspectives. Environmental Management, Environmental Management 34(1):S1-S1334.

Lu, D.; Batistella, M.; Moran, E.; Mausel, P. 2004a. Application of spectral mixture analysis to Amazonian land-use and landcover classification. International Journal of Remote Sensing, 25 (23):5345-5358 .

Lu, D. S.; Batistella, M.; Moran. Multitemporal spectral mixture analysis for Amazonian land-cover change detection. 2004b. Canadian Journal of Remote Sensing, 30(1):87-100.
Lu, D. S.; Mausel, P.; Brondizio, E.; Moran, E. 2003a. Classification of successional forest stages in the Brazilian Amazon basin. Forest Ecology and Management, 181(3): 301-312.

Lu, D. S.; Moran, E.; Batistella, M. Linear mixture model applied to Amazonian vegetation classification. 2003b. Remote Sensing of Environment, 87(4):456-469.

Lucas R. M.; Honzak, M.; Curran P. J.; Foody, G. M.; Milne, R.; Brown T.; Amaral, S. 2000. Mapping the regional extent of tropical forest regeneration stages in the Brazilian Legal Amazon using NOAA AVHRR data. International Journal of Remote Sensing, 21(15):2855-2881

Martins, P. S. 2005. Evolutionary dynamic in amazonian "Roça de caboclo". Estudos Avançados, 19(53):209 -220 (in Portuguese, with abstract in English).

MCT. 2004. First Brazilian inventory of anthropogenic greenhouse gas emissions. 88 p. Disponível em: http://www.mct.gov.br/upd_ blob/0024/24593.pdf. Acesso em: 19 set 2008 (in Portuguese).

Miguez, S. F.; Fraxe, T. D. J. P.; Witkoski A. C.2007. The traditional and the modern in family farmer in amazonian: The introduction of the technology in the lowland of Solimóes river, Amazonas State. In: VII Congresso Brasileiro de Sistemas de Produção, 2007, Fortaleza - CE. Disponível em: http://www.cnpat.embrapa.br/ sbsp/anais/Trab_Format_PDF/96.pdf. Acesso em: 16 set 2008 (in Portuguese).

Moran, E. F.; Brondizio, E.; Mausel, P.; Wu, Y. 1994. Integrating Amazonian Vegetation, Land-Use, and Satellite Data. Bioscience, 44(5):329-338.

Moran, E. F.; Brondizio, E.; Tucker, J. M.; da Silva-Forsberg, M. C.; Mccracken, S.; Falesi, 2000.I. Effects of soil fertility and land-use on forest succession in Amazonia. Forest Ecology and Management, 139(1-3):93-108.

NASA. 2008. Orthorectified Landsat Enhanced Thematic Mapper $(E T M+)$ Compressed Mosaics. Washington, DC, Disponível em: https://zulu.ssc.nasa.gov/mrsid/. Acesso em: 13 mar 2006.

NeeffT.; Lucas, R. M.; Dos Santos, J. R.; Brondizio, E. S.; Freitas, C. C. 2006. Area and age of secondary forests in Brazilian Amazonia 1978-2002: An empirical estimate. Ecosystems, 9(4):609-623.

Nelson, R. F.; Kimes, D. S.; Salas, W. A.; Routhier, M. 2000 Secondary forest age and tropical forest biomass estimation using thematic mapper imagery. Bioscience, 50(5): 419-431.

Neter, J.; Wasserman, W. 1974. Applied Linear Statistical Models Regression, Analysis of Variance, and Experimental Designs. Richard D. Irwin, INC, Georgetown, Ontario. 842 pp.

Nobre, C. A.; Nobre, A. D. 2002. The carbon balance of brazilian amazon. Estudos Avançados, 16(45):81-90 (in Portuguese, with abstract in English).

Nobre, C. A.; Sellers, P. J.; Shukla, J. Amazonian Deforestation and Regional Climate Change.1991.Journal of Climate, 4(10): 957-988.

Olson, D. M.; Dinerstain, E.; Wikramanayake E. D.; Burgess N. D.; Powell, G. V. N.; Underwood, E. C.; D’Amico, J. A.; Itoua, I.; Strand, H. E.; Morrison, J. C.; Louks, C. J.; Allnutt T. F.; Ricketts, T.H.; Kura, Y.; Lamoreux, J. F.; Wettengel, W. 
W.; Hedao, P.; Kassem, K. R. 2001. Terrestrial Ecoregions ofthe World: A New Map of Life on Earth. BioScience, 51(11):933-938

Odum, E. P. The Strategy of Ecosystem Development 1969. Science, 164(3877): 262 - 270

Perz, S. G.; Skole, D. L. 2003. Social determinants of secondary forests in the Brazilian Amazon. Social Science Research, 32(1):2560.

Roberts, D. A.; Numata, I.; Holmes, K.; Batista, G.; Krug, T.; Monteiro, A.; Powell, B.; Chadwick, O. A. 2002.Large area mapping of land-cover change in Rondonia using multitemporal spectral mixture analysis and decision tree classifiers. Journal of Geophysical Research-Atmospheres, 107(D20), 8073.

Shimabukuro, Y. E.; Smith, J. A. 1991.The Least-Squares Mixing Models to Generate Fraction Images Derived from RemoteSensing Multispectral Data. Ieee Transactions on Geoscience and Remote Sensing, 29(1):16-20.

Spiegel, M. R. 1977. Statistics. São Paulo: McGraw-Hill do Brasil, 580 pp (in Portuguese).
Steininger, M. K. 2000. Satellite estimation of tropical secondary forest above-ground biomass: data from Brazil and Bolivia. International Journal of Remote Sensing, 21(6-7):139-1157.

Stouffer, P. C.; Bierregaard R. O.; Strong, C.; Lovejoy, T. E. Longterm landscape change and bird abundance in Amazonian rainforest fragments. 2006. Conservation Biology, 20( 4): 12121223.

Szott, L. T.; Palm, C. A.; Buresh, R. J. 1999. Ecosystem fertility and fallow function in the humid and subhumid tropics. Agroforestry Systems, 47(1-3):163-196.

Teixeira, C. O. 2005. Sustainable development in protected areas: The "naturalization" of social . Revista Brasileira de Ciências Sociais, 20(59):51- 66 (in Portuguese).

Recebido em 10/11/2008

Aceito em 10/11/2009 
